\title{
Correlation of Bending Test Varying the Length Between Supports to Determine Longitudinal Modulus of Elasticity
}

\author{
Edson Fernando Castanheira Rodrigues ${ }^{1, *}$, André Luis Christoforo ${ }^{2}$ \\ ${ }^{1}$ School of Civil Engineering, University of Uberaba, Uberaba, Brazil \\ ${ }^{2}$ Department of Civil Engineering, Federal University of São Carlos, São Carlos, Brazil
}

Email address:

edson.engcivil.projetos@gmail.com (E. F. C. Rodrigues)

${ }^{*}$ Corresponding author

\section{To cite this article:}

Edson Fernando Castanheira Rodrigues, André Luis Christoforo. Correlation of Bending Test Varying the Length Between Supports to Determine Longitudinal Modulus of Elasticity. International Journal of Materials Science and Applications. Vol. 8, No. 2, 2019 , pp. $21-24$. doi: $10.11648 /$ j.ijmsa.20190802.11

Received: May 14, 2019; Accepted: June 19, 2019; Published: June 29, 2019

\begin{abstract}
The large amount of wood in Brazil related to the numerous uses of this material stimulates many studies to be carried out in order to use this raw material increasingly in a rational and adequate way. Compared with concrete and steel, wood presents an excellent relation between mechanical strength and its mass, beauty, low energy consumption for its processing, good thermal insulation and easy workability. In order to make the best use of wood, this work proposes to study the correlation between the values of the longitudinal modulus of elasticity (E) obtained in the 3-point bending test with a $14 \mathrm{H}$ and $21 \mathrm{H}(\mathrm{H}=$ height of cross-sectional area) of specimen measurement between the supports. The data were analyzed through linear regression analysis, thus, three correlations were calculated between values from $14 \mathrm{H}$ of span length to the other $21 \mathrm{H}$ of span length in the test for a particular correlation of each hardwood species (Peroba Rosa and Eucalyptus Tereticornis) and the third one was generalized for the use in more hardwood species. Thus, the correlation of the longitudinal modulus of elasticity for the species of the hardwood group was possible for: Peroba Rosa (Aspidosperma polyneuron) with 35 specimens and Eucalyptus Tereticornis (Eucalyptus tereticornis) with 33 specimens.
\end{abstract}

Keywords: Linear Regression, Hardwood, Relation, Stiffness, Bending Test

\section{Introduction}

Brazil is one of the most important countries in the world in relation to the forest sector, since it has a certified forest area equals to 6, 378, 006 ha (hectare) in its different biomes, each one with specific characteristics of the flora [1].

In relation to other materials such as concrete, plastic, steel and aluminum, wood has a number of advantages, such as beauty, high mechanical resistance to mass, low energy consumption for its processing, good thermal insulation, easy workability [2].

The physical and mechanical characteristics and relative abundance of this material enable its application for uses in interior finishes to large structures such as pavilions, roofs and bridges. Wood presents environmental advantages when compared to other building materials (cement, concrete, steel and aluminum), because it is recyclable, renewable, biodegradable and requires low energy needs for its processing [3-5].

Regarding the importance of wood, it is necessary to carry out studies on obtaining its physical and mechanical characteristics. Among the mechanical properties of materials used in the design of a structure, highlights the longitudinal modulus of elasticity (MOE), enabling the setting to provide displacement and deformations in structural components subjected to the action of the imposed loads (limit state) [6-7].

The modulus of elasticity measures the stiffness of the piece, however, to have it obtained, it is necessary to carry out the test with the utmost care, as an example, the definition of the length of the span between supports in the static bending test is preponderant to reach real values for the longitudinal modulus of elasticity of the specimen.

In Brazil, the design of wood structures is regulated by ABNT NBR 7190 (1997) (Wood Structures Project) standard [8], which establishes the rules for the obtainment of the longitudinal modulus of elasticity of wood through the 
3-point bending test, which can be found in its Annex b as well as the measurements of the specimen used and the test procedure. In this test, dimensions of the specimen are prescribed so that the ratio $\mathrm{L} / \mathrm{H}(\mathrm{L}=$ span between supports, $\mathrm{H}=$ height of the cross section of the specimen) is equal to $21 \mathrm{H}$. According to $[3,9,10]$, for span length greater than or equal to $21 \mathrm{~h}$, the shear action in the determination of the arrow and in the real E can be neglected.

Yoshihara et al. [11] performed the comparison between longitudinal (E) and transverse (G) modulus of elasticity values by the transverse vibration test and the 3 -point bending test with spans between supports varying from $\mathrm{L}=16 \mathrm{~h}(\mathrm{H}=$ height of the cross section of the specimen) to $\mathrm{L}=4.33 \mathrm{H}$. Thus, the values of $E$ and $G$ were analyzed for the tested species of conifers: Sitka spruce (Picea sitchensis Carr.), Western hemlock (Tsuga heterophylla Sarg.), akamatsu (Japanese red pine, Pinus densiflora D. Don) and balsa (Ochroma lagopus Sw.), and for hardwoods: Yellow poplar (Liriodendron tulipfera L.) and Shioji (Japanese ash, Fraxinus spaethiana Lingelsh.). According to table 1 contained in the paper, it can be inferred that the smaller the span between supports in relation to the height of the specimen in the 3-point bending test, the greater the influence of shearing on the arrow, as a consequence, the smaller the modulus of elasticity, if measured with span less than $21 \mathrm{H}$.

Braz et al. [14] determined the mechanical properties of the Toona ciliata wood, including the longitudinal modulus of elasticity determined by the 3-point bending test, the dimensions of the specimens followed ABNT MB 26/40 [15], with tests performed according to the standard NBR 7190 (1997) [8]. Test specimens with dimensions of $2.0 \times 2.0 \times 30.0$ $\mathrm{cm}(\mathrm{cm}=$ centimeter $)$ were used to perform the static bending tests of the wood in order to obtain the longitudinal modulus of elasticity (MOE) at the ratio of $\mathrm{L} / \mathrm{H}=14$ (length between supports divided by the height of test piece).

Babiak et al. [12] prepared specimens made of spruce wood (Picea Abies L.) and oak wood (Quercus robur L.) with dimensions of 20 (radial) $\times 20$ (tangential) $\times 300 \mathrm{~cm}$ (longitudinal) to be tested in a Three and four point bending test to find out some mechanical properties of the species studied, between them, the modulus of elasticity, according to the standard EN 310 [13], for measurements in three-point bending, the support span was adjusted to $l_{0}=12 \times \mathrm{H}$.

This work objectify the study of the correlation between the longitudinal modulus of elasticity determined in the 3-point static bending test with a span length between supports of $14 \mathrm{H}$ and $21 \mathrm{H}(\mathrm{H}=$ height of the cross-sectional area of the specimen). This study is performed by linear regression analysis, which considers correlation equations for each studied species in order to take advantage of previous studies to the standard NBR 7190 (1997) [8], as well as a generalized equation for the hardwood group, from the two species data presented in the work.

\section{Material and Methods}

All tests were carried out on the Laboratory of Wood and
Wood Structures (Laboratório de Madeira e de Estruturas de Madeira - LaMEM), at the São Carlos Engineering School (EESC), University of São Paulo (USP).

Three-point bending tests were performed with length between supports of $\mathrm{L}=14 \mathrm{H}$ and $\mathrm{L}=21 \mathrm{H}$ for the determination of the longitudinal modulus of elasticity value $\mathrm{E}_{(14)}$ and $\mathrm{E}_{(21)}$, respectively. The 3-point bending test performed is prescribed by standard ABNT NBR 7190 (1997) (Wood Structures Project) in its Annex B, which shows the dimensions of the specimen as well as the test procedure.

In this work, the three-point bending test was performed in an adapted manner for deformations (arrows) in the test, limited to a limit of $\mathrm{L} / 200$, ( $\mathrm{L}$ is the length between supports), so that the piece of wood tested does not exceed the elastic regime into the plastic one, and the test is also adapted for ratio of $\mathrm{L} / \mathrm{H}=14$.

The species studied were: Peroba Rosa (Aspidosperma polyneuron) with 35 test specimens, Eucalyptus Tereticornis (Eucalyptus tereticornis) with 33 specimens, always with a moisture content of $12 \%$ based on the NBR 7190 (1997) [8]. The values of $\mathrm{E}_{(14)}$ and $\mathrm{E}_{(21)}$ were determined for the species of the hardwood group studied by linear regression analysis of the results, the equation that represent this relation was reached for each species and the third one for both, generalizing the analysis.

The arrows were measured by comparator clock, located only in the middle of the span (point 1), $\mathrm{P}$ is the value of the applied load, $\mathrm{L}$ the length of the span between supports $(14 \mathrm{H}$ and $21 \mathrm{H}$ ) as it can be seen in Figures 1 and 2.

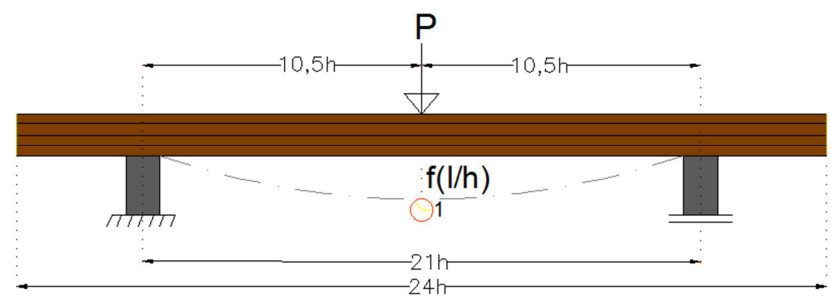

Source: author's collection

Figure 1. Representation of the 3-point bending test (span length between supports equal to $21 \mathrm{H}$ ) with its respective comparator clock.

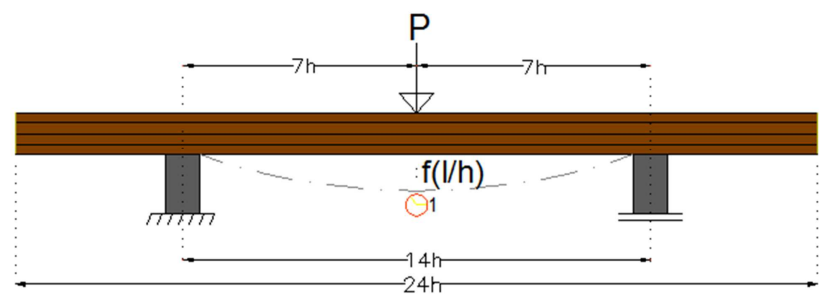

Source: author's collection

Figure 2. Representation of the 3-point bending test (span length between supports equal to $14 H$ ) with its respective comparator clock.

Two 3-point static bending tests were performed, one with a span length between supports equal to $14 \mathrm{H}$ (14 times the height of the specimen) according to figure 1 , and the other 
one with a span length between supports equals to $21 \mathrm{H}(21$ times the height of the specimen) as shown in figure 2 .

\subsection{Three-Point Static Bending Test (14H)}

The 3-point static bending test was elucidated as ABNT NBR 7190 (1997) [8] describes in its appendix B (determination of properties for the structural design), but with a length between supports of $14 \mathrm{H}$. The arrow always limited to $\mathrm{L} / 200$ so that it does not exceed the limit of proportionality required in the Brazilian standard.

The 3-point simple bending test with a length between supports equals to $14 \mathrm{H}$ is used to determine the longitudinal modulus of elasticity $E_{(14)}$, which is shown in figure 1 . The equation used to obtain the longitudinal modulus of elasticity $\mathrm{E}_{(14)}$ is based on the virtual forces method, which uses only the part due to bending in the determination of the arrow, according to equation 1 .

$$
v(1)=\frac{P \cdot L^{3}}{48 \cdot E(14) \cdot I}
$$

In equation $1, \mathrm{P}$ is the load applied in the middle of the span between supports, $\mathrm{L}$ is the length between supports, $\mathrm{E}_{(14)}$ is the longitudinal modulus of elasticity to be determined and I is the moment of inertia.

\subsection{Three-Point Static Bending Test (21H)}

The 3-point simple bending test with a span length between supports of $21 \mathrm{H}$ is used to determine the longitudinal modulus of elasticity $\mathrm{E}_{(21)}$, which is shown in figure 2 .

The 3-point bending test was elucidated as ABNT NBR 7190 (1997) [8] describes in its appendix B (determination of properties for the structural design). However, in a non-destructive manner with the arrow always limited to $\mathrm{L} / 200$, so that the limit of proportionality required in the Brazilian standard is not exceeded. Equation 2 is used, which is equal to equation 1, but a higher longitudinal modulus of elasticity was generated, since for span lengths between supports equal to or greater than $21 \mathrm{H}$, the shear effect can be neglected.

$$
v(1)=\frac{P \cdot L^{3}}{48 \cdot E(21) \cdot I}
$$

In equation $2, \mathrm{P}$ is the load applied in the middle of the span between supports, $\mathrm{L}$ is the length between supports, $\mathrm{E}_{(21)}$ is the longitudinal modulus of elasticity to be determined and I is the moment of inertia.

\section{Results and Discussion}

Table 1 shows the mean values for the tests of the longitudinal modulus of elasticity $\mathrm{E}_{(14)}$ and $\mathrm{E}_{(21)}$, respectively. The equivalence between the values of the MOE by the Tukey test is confirmed if there are values marked with the same letter. In these tables the coefficient of variation (C.V.) can still be seen for each group of specimens tested.
Table 1. Equivalence analysis using the Tukey test for the results of the static bending tests for $E_{(14)}$ and $E_{(2 l)}$.

\begin{tabular}{lllll}
\hline $\mathbf{E}_{(\mathbf{1 4})} \mathbf{e} \mathbf{E}_{(\mathbf{2 1})}-$ Unit Mpa & & & & \\
\hline M. values & $\mathbf{E}(\mathbf{1 4})$ & C.V. & $\mathbf{E ( 2 1 )}$ & C.V \\
\hline P. Rosa & $9296 \mathrm{~B}$ & 0,125 & $10305 \mathrm{~A}$ & 0,128 \\
E. Tereticornis & $13588 \mathrm{~B}$ & 0,145 & $15504 \mathrm{~A}$ & 0,148 \\
\hline
\end{tabular}

M. = Medium

The results of Table 1 for the values of the longitudinal modulus of elasticity for spans lengths of $14 \mathrm{H}$ and $21 \mathrm{H}$ between supports indicated by the Tukey equivalence test that for the two species tested there was no equivalence for their respective longitudinal modulus of elasticity $\mathrm{E}_{(14)} \times \mathrm{E}_{(21)}$, thus indicating that it is necessary to carry out the test with a distance between supports of $21 \mathrm{H}$, which the Brazilian standard recommends for 3-point static bending test.

In the impossibility of performing tests with a span length between supports equals to or greater than $21 \mathrm{H}$, and considering all the studies and trials already carried out throughout history, such as those that were performed based on the old MB $-26 / 40$ Brazilian standard [15] or in other international standards and also for works, as realized by the study [14], a linear regression analysis was carried out based on the results of the tests of this work for the wood of Peroba Rosa and Eucalyptus Tereticornis so that the values of the longitudinal modulus of elasticity obtained through the three-point static bending test with a span length of $14 \mathrm{H}$ can be used without any damage.

For the Peroba rosa species, linear regression analysis resulted in equation 3 .

$$
E(\text { real })=1,266 \cdot E(14)-932
$$

With $\mathrm{r}=0.87$, which indicates a reliable relation for equation 3 , and $\mathrm{E}_{\text {(real) }}$ longitudinal modulus of elasticity equivalent to the 3-point bending test with span between supports equals to $21 \mathrm{H}$, and $\mathrm{E}_{(14)}$ is the modulus of elasticity determined by the three-point bending test with a span between supports equals to $14 \mathrm{H}$.

For the wood species of Eucalyptus Tereticornis, the same linear regression analysis was performed, which resulted in equation 4.

$$
E(\text { real })=1,142 \cdot E(14)+104
$$

With $\mathrm{r}=0.91$, which indicates a reliable relation, and $\mathrm{E}_{(\text {real })}$ is the longitudinal modulus of elasticity equivalent to the 3 -point bending test with span length between supports equals to $21 \mathrm{H}$, and $\mathrm{E}_{(14)}$ is the modulus of elasticity determined through the three-point bending test with a span length between supports equals to $14 \mathrm{H}$.

From the data of the two species, a linear regression analysis was performed among these species in order to generalize the use of such equation for more woods from the group of hardwoods for structural use, presented in equation 5.

$$
E(\text { real })=1,161 \cdot E(14)+11
$$


With $\mathrm{r}=0.91$, which indicates a reliable relation, and $\mathrm{E}_{(\text {real })}$ is the longitudinal modulus of elasticity equivalent to the 3-point static bending test with a span length between supports equals to $21 \mathrm{H}$, and $\mathrm{E}_{(14)}$ is the longitudinal modulus of elasticity determined through the test of 3-point static bending test for the two species of this work with span length between supports equals to $14 \mathrm{H}$.

\section{Conclusions}

The results of this study permit us to conclude:

For values determined in the two three-point static bending tests, one with a span length between supports equals to $14 \mathrm{H}$ and another with $21 \mathrm{H}$ for the longitudinal modulus of elasticity, Tukey's equivalence test demonstrated the non-equivalence between these values.

(1) The non-equivalence between results of the two tests led to the study of linear regression analysis to determine an equation that correlates the values of the longitudinal modulus of elasticity obtained by each test.

(2) One equation was obtained generalizing the values determined for the two species of this work, in order to be used for more species of the hardwoods group.

(3) The present work suggests more studies to be carried out in the sense of assuring more accuracy of the linear regression equations for the studied species, as well as the generalized analysis to be used for more species of the hardwood group.

\section{References}

[1] Cavalheiro, R. S.; Almeida, D. H.; Almeida, T. H.; Christoforo, A. L.; Larh, F. A. R. Estimation of modulus of elasticity in static bending of wood in structural dimensions as a function of longitudinal vibration and density, Current Journal of Applied Science and Technology, London, v.26, n. 1, p. 1-8, february, 2018.

[2] Vidal, J. M.; Evangelhista, W. V.; Silva, J. C.; Jankowsky, I. P. Preservação de madeiras no Brasil: Histórico, cenário atual e tendências, Ciência Florestal, Santa Maria - RS, v. 25, n. 1, p. 257-271, jan./mar. 2015.

[3] Segundinho, P. G. A.; Regazzi, A. J.; Poletti, F. S.; Paula, M. O.; Mendonça, A. R.; Gonçalves, F. G. Variação dos módulos de elasticidade e ruptura em madeira de Cedro-Australiano por meio de ensaios não destrutivo e destrutivo, Ciência Florestal, Santa Maria - RS, v. 28, n. 3, p. 1163-1178, jul./set. 2018.
[4] Marques, L. E. M. M. O papel da madeira na sustentabilidade da construção. 2008. 111 f. Dissertação (Mestrado Integrado em Engenharia Civil) - Departamento de Engenharia Civil, Faculdade de Engenharia da Universidade do Porto, Porto, 2008.

[5] Georgiopoulos, P. and Kontou, E. The effect of wood-fiber type on the thermomechanical performance of a biodegradable polymer matrix, J. Appl. Polym. Sci., v. 132, p. 1-10, march. 2015.

[6] Icimoto, F. H.; Ferro, F. S.; Almeida D. H.; Christoforo, A. L.; Lahr, F. A. R. Influence of the wood specimen position on calculus of bending modulus of elasticity, International Journal of Materials Engineering, v. 3, n. 3, p. 41-46, may. 2013.

[7] Guan, C.; Liu, J.; Zhang, H.; Wang, X.; Zhou, L. Evaluation of modulus of elasticity and modulus of rupture of full-size wood composite panels supported on two nodal-lines using a vibration technique, Construction and Building Materials, v. 218, p. 64-72, 2019.

[8] Associação Brasileira De Normas Técnicas - ABNT. NBR 7190 (1997). Projeto de estruturas de madeira. Rio de Janeiro, 107 p., 1997.

[9] Morales, E. A. M.; Kondo, H. K. Barbosa J. C.; Campos, C. I.; Lahr, F. A. R.; Christoforo, A. L. Evaluating a test parameter in static bending for Pinus sp. wood. Advanced Materials Research. V. 1025-1026, p. 196-199, September. 2014.

[10] Lahr, F. A. R.; Christoforo, A. L.; Panzera, T. H.; Silva D. A. L.; Gonçalves, D. Anisotropy influence in obtaining stiffiness property in bending of Brazilian wood species. International Journal of materials Engineering, v. 4, n. 3, p. 92-96, may. 2014.

[11] Yoshihara, H.; Kubojima, Y.; Nagaoka, K.; Ohta, M. Measurement of the shear modulus of wood by static bending tests. Journal of Wood Science, v. 44, n. 1, p. 15-20, february. 1998.

[12] Babiak, M.; Gaff, M.; Sikora, A.; Hysek, Š. Modulus of elasticity in three- and four-point bending of wood. Composite Structures, v. 204, n. 15, p. 454-465, November. 2018.

[13] EN 310. Wood-based panels. Determination of modulus of elasticity in bending and of bending strength. European Committee for Standardization, Brussels, Belgium; 1993.

[14] Braz, L. R.; Oliveira, J. T. S; Rodrigues, B. P.; Arantes, M. D. C. Propriedades físicas e mecânicas da madeira de toona ciliata em diferentes idades. Floresta, Curitiba - PR, v. 43, n. 4, p. 663-670, out/dez. 2013.

[15] Associação Brasileira De Normas Técnicas - ABNT. MB 26/40 (1940). Ensaios físicos e mecânicos de madeiras. Rio de Janeiro, 1940. 